\title{
AIR FLOW OVER REAR DECK OF BATTLESHIP PENNSYLVANIA.*
}

\author{
BY
}

\section{A. F. ZAHM, Ph.D.}

Bureau of Construction and Repair, Navy Department.

In January, I9I8, the Navy model of the battleship Pennsylvania was tested in the $8^{\prime} \times 8^{\prime}$ wind tunnel to determine aerodynamical and structural conditions suitable for landing light airplanes upon the after-deck of the full-scale ship. The model was tested first in its natural condition, then with a shelving deck placed above the rear part in a manner presently to be described.

The experiments here outlined were made by Messrs. R. H. Smith, W. H. Gornall and G. J. Chaillet; the illustrations were prepared by Mr. M. T. Birch-all members of the Aeronautics Staff. Major B. I. Smith, U. S. M. C., indicated what explorations should be made and under what conditions.

TEST OF MODEL IN ITS NATURAL CONDITION.

Battleship and Original Model._Fig. I gives the general appearance of the Pennsylvania model constructed to a scale of I in 48. The chief dimensions of the ship are: length 600 feet, beam 97 feet, height of the rear deck above the water line 25 feet.

Method of Test.-The unaltered model was first placed upright on the floor of the tunnel, so that its plane of symmetry was midway between the side walls, and its rear deck was under the window in the tunnel ceiling, where it could easily be observed and photographed. The speed of the general air stream was then held at 30 miles per hour, and the velocity about the model was measured with a pitot-tube held in the vicinity of the stern at distances corresponding to 20 -foot intervals horizontally rearward, and 5, I5, and 25 feet vertically, above the main deck of the full-sized craft. Table I and Fig. 2 give the wind speed and the lines of equal velocity at these stations; first in the plane of symmetry, then in a parallel plane 24 feet from it.

Fine steel wires were then strung across the tunnel at rear-

\footnotetext{
* Communicated by the Author.
} 
FIG. I.

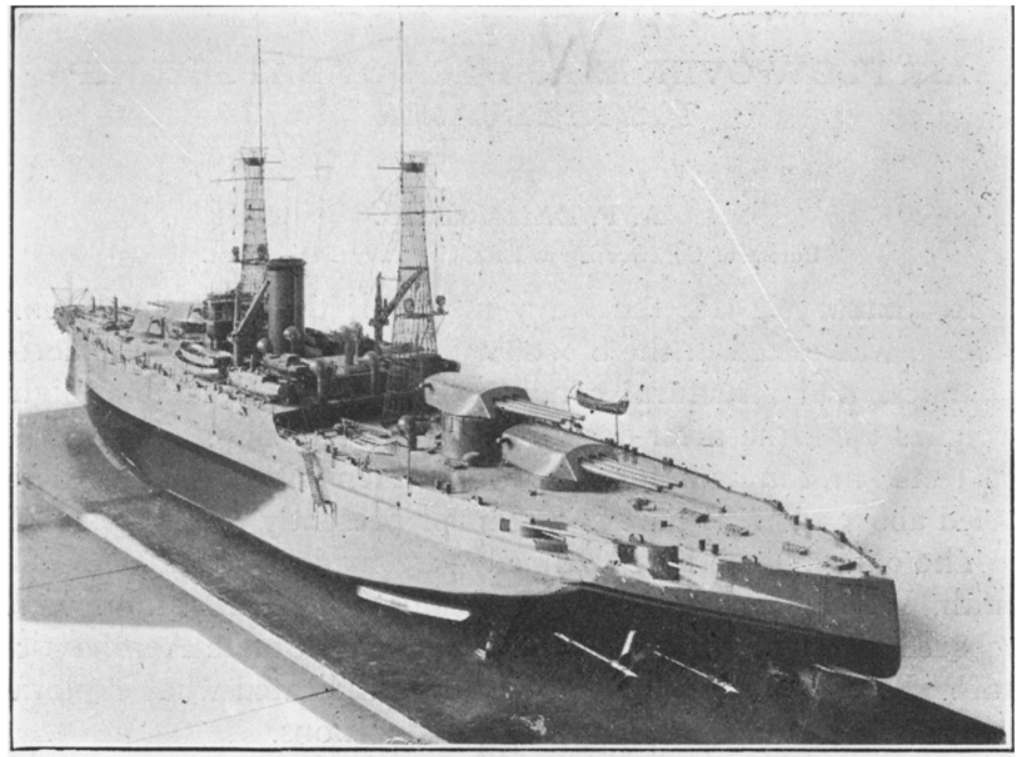

Model of Pennsylvanic.

FIG. 2.

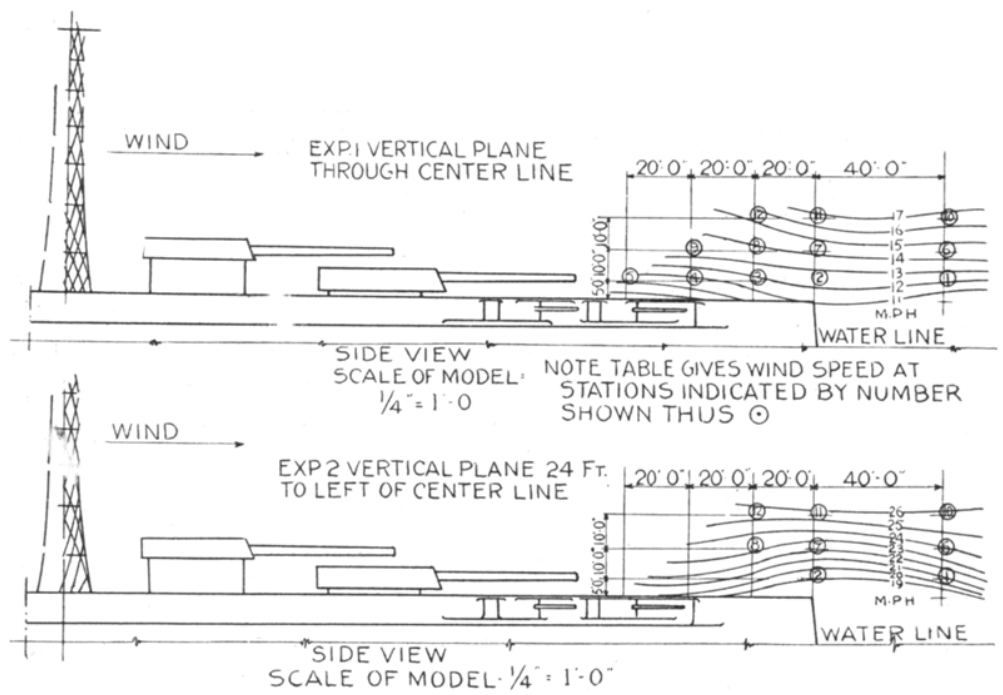

Flow over rear deck of Fennsyivanna al 30 Iv.t.l1. 
ward distances corresponding to 48 feet on the full-size craft, and to these were moored, at 8-foot intervals, short silk threads, as portrayed in Fig. 3. With long fluttering threads cleaner photographs were obtained by stopping the wind after the threads had assumed their natural positions. Fig. 4 illustrates the direction of flow, thus observed, in three horizontal planes whose distances above the rear deck were, respectively, 24, 36 and 48 feet.

The model was then held with its plane of symmetry horizontal, its deck under the ceiling window, and its base screwed to planking parallel to the side wall. The same general scheme was

TABLE I.

Buttleship Pennsylvania Model. Velocity of Air over Rear Deck and Stern. Wind Speed 30 Miles per Hour.

\begin{tabular}{|c|c|c|}
\hline \multirow{2}{*}{ Station } & \multicolumn{2}{|c|}{$\begin{array}{c}\text { Air speed in miles per hour at various } \\
\text { stations }\end{array}$} \\
\hline & $\begin{array}{l}\text { In vertical plane } \\
\text { through centre line }\end{array}$ & $\begin{array}{l}\text { In vertical plane } \\
24 \text { feet to left of } \\
\text { centre line }\end{array}$ \\
\hline I & I I . 5 & 20.4 \\
\hline 2 & 12.2 & I9. I \\
\hline 3 & I I . I & $\ldots$ \\
\hline 4 & 10.6 & $\ldots$ \\
\hline 5 & 9.9 & $\ldots$ \\
\hline 6 & 14.6 & 24.6 \\
\hline 7 & I 4.1 & 22.4 \\
\hline 8 & 13.7 & 23.4 \\
\hline 9 & 13.3 & $\ldots$ \\
\hline IO & 16.3 & 25.1 \\
\hline I I & I 6.5 & 25.7 \\
\hline I 2 & $\mathrm{I} 4.9$ & 25.4 \\
\hline
\end{tabular}

employed for observing the flow; first in the plane of symmetry, then in a parallel plane 24 feet distant on the ort side, as shown in Fig. 4 and Fig. 5.

Results.-The equal-velocity lines in Fig. 2 and the direction lines in Fig. 4 show a pronounced interruption of the airflow near the deck, due mainly to eddies set up by the rear turret. This disturbance is unchanged when the rear turret is swung through $90^{\circ}$, as illustrated by Fig. 6.

Conclusion.-Difficulty would be experienced in landing airplanes in the disturbed air over the rear deck of the Pennsylvania battleship in its unaltered condition. A shelving deck above the 
plane of the rear turret would insure a smoother flow of the air. It was, therefore, requested that such a deck be added to the model and given a test in the tunnel.

\section{TEST OF THE MODEL PROVIDED WITH SHELVING DECK.}

The Shelving-Deck Model.-The original model was now tested; first with a small shelf deck, then with a larger one. In the scale of the full-size craft these measured, respectively, $80^{\prime} \times 120^{\prime}$ and $I^{\prime} \mathrm{O}^{\prime} \times \mathrm{I}^{\prime} 80^{\prime}$. The smal'er shelf deck was placed 5 feet above

\section{FIG. 3.}

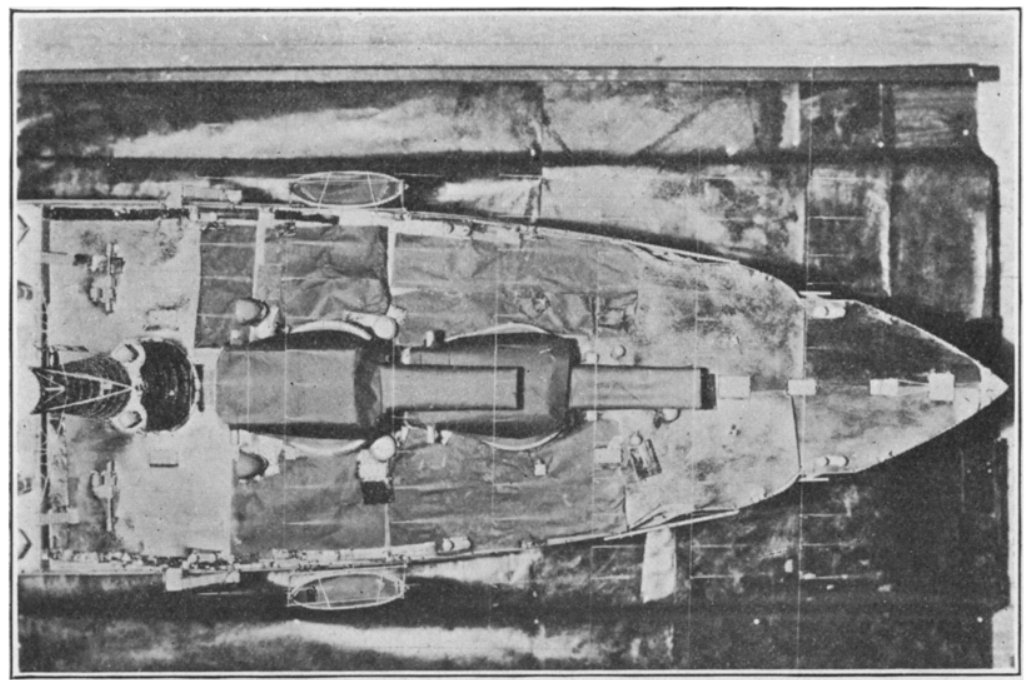

Short threads over rear deck of Pennysivania model.

the main deck, and extended from a point just under the guns of the rear turret to a point just over the stern. The larger deck was ro feet above the main deck and extended from the mast, rearward, over both turrets and over the stern.

Method of Test.-Substantially the same method of tracing the direction of the airflow was used with the model having the shelving deck as with the original one. Fig. 7 shows the arrangement of the wires and the general appearance of the larger deck. The wind speed for these latter tests was 20 miles per hour.

Results.-Fig. 8 reveals a continued disturbance of a minor 
FIG. 4.

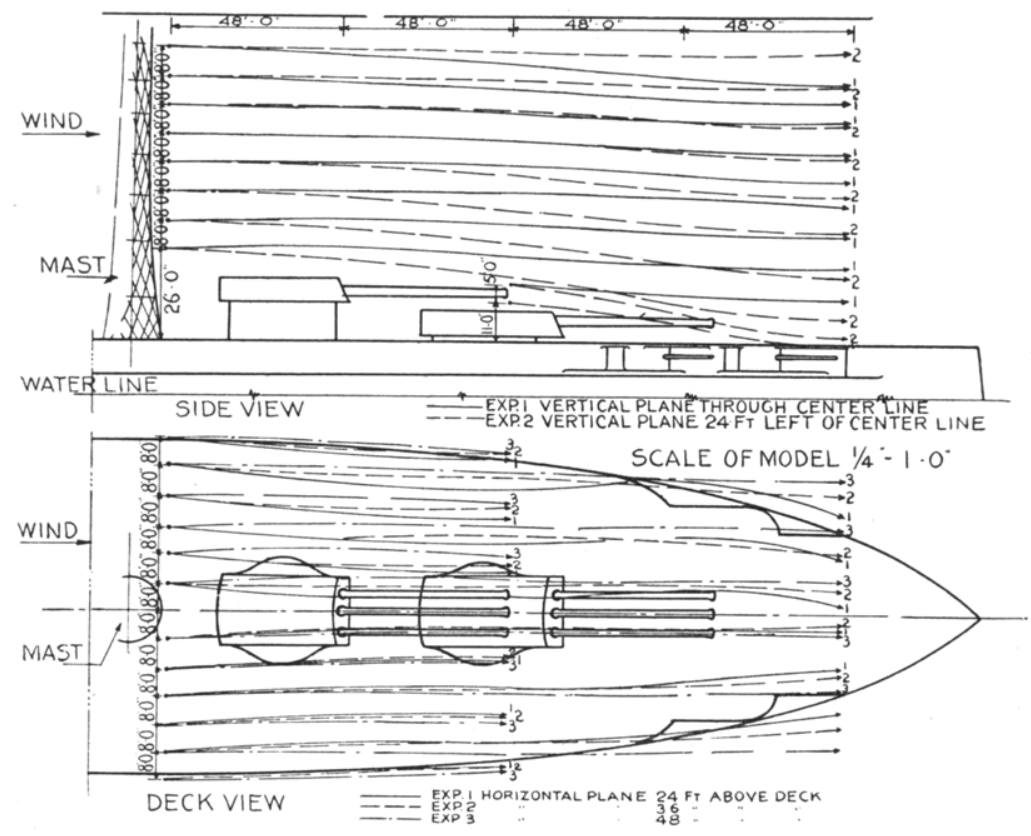

Direction of air flow over rear deck of Pennsylvania model.

Fi.G. 5

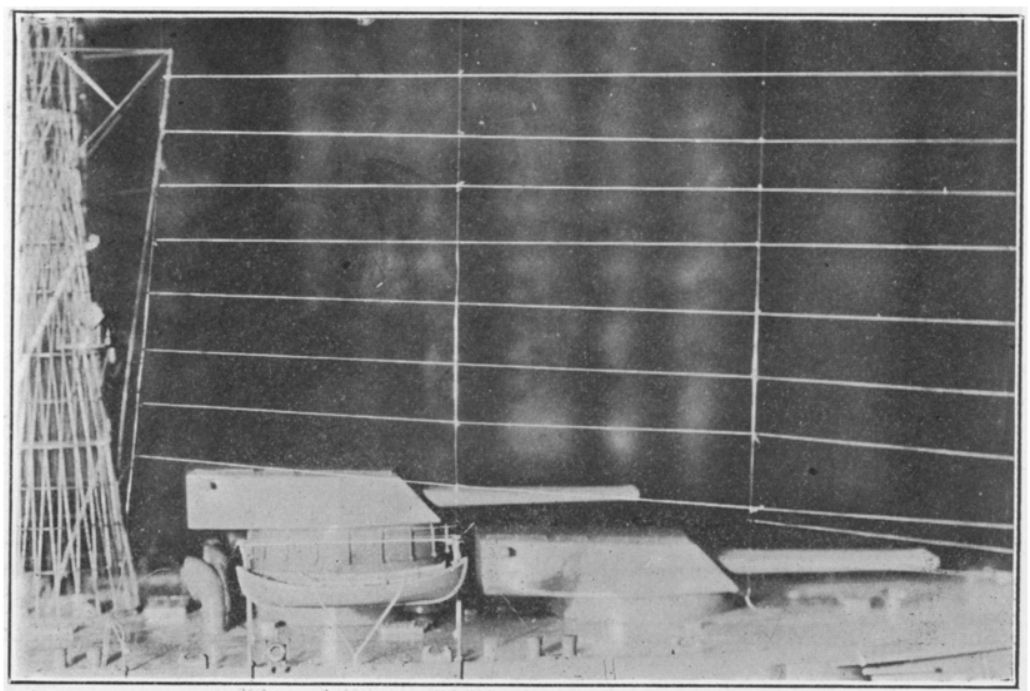

Stream-line threads in plane of symmetry over rear of Pennsylvania model, lying on its side. VOL. I88, No. II $25-29$ 
FIG. 6.

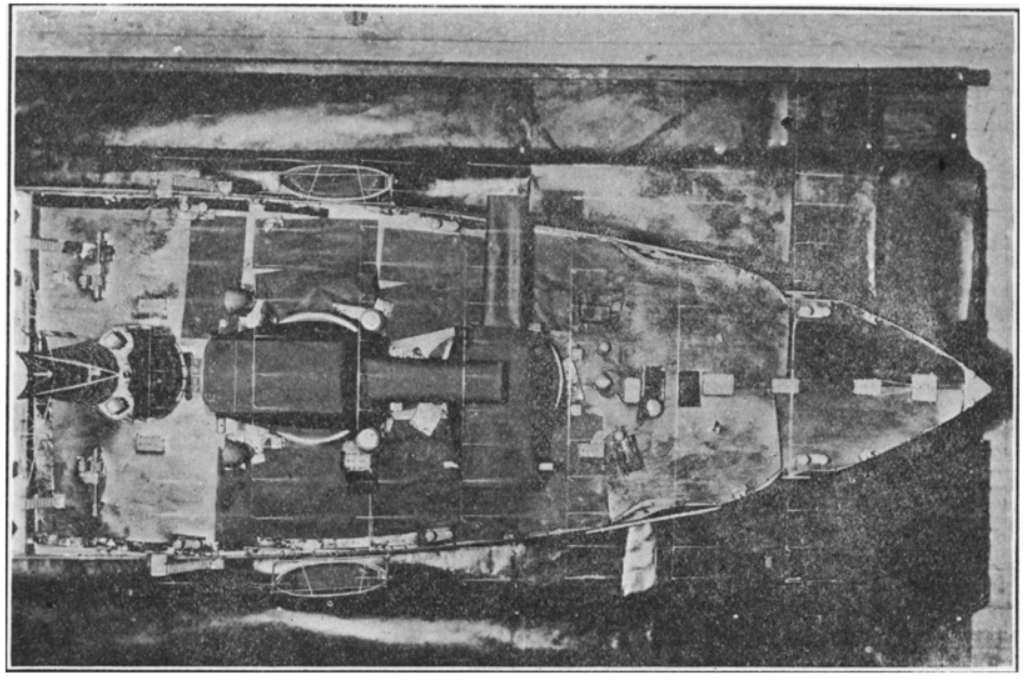

Flow over rear deck of Pennsylvania, with rear turret set athwart ship.

FIG. 7.

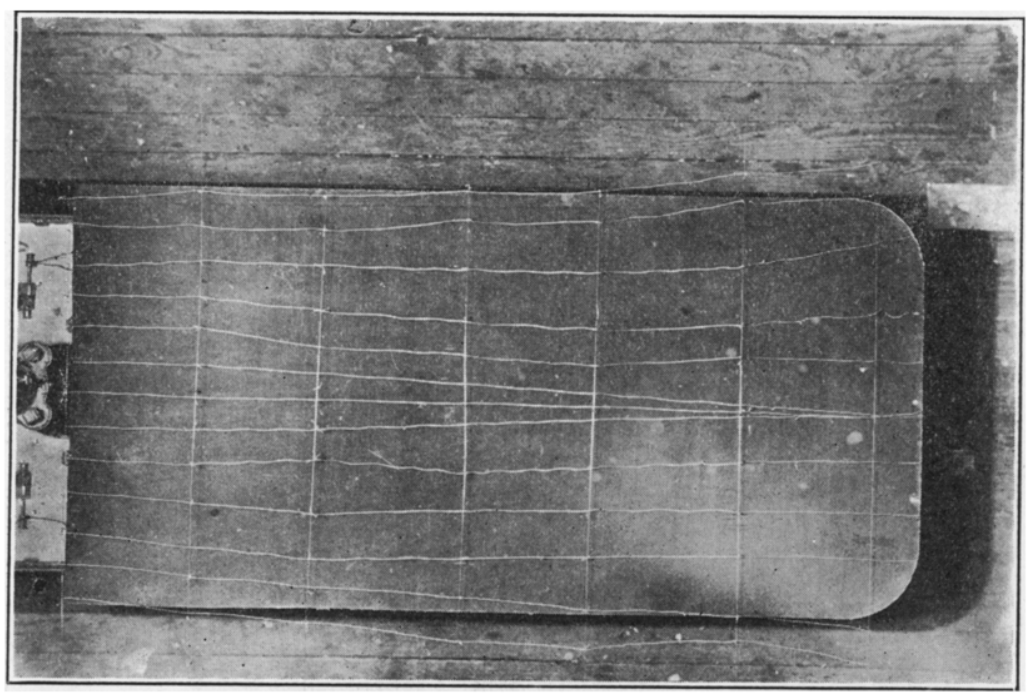

Shelving deck and threads over rear of Pennsylou nio model. 
Sept., igig.] Arr Flow Over Deck of Pennsylvania. 395
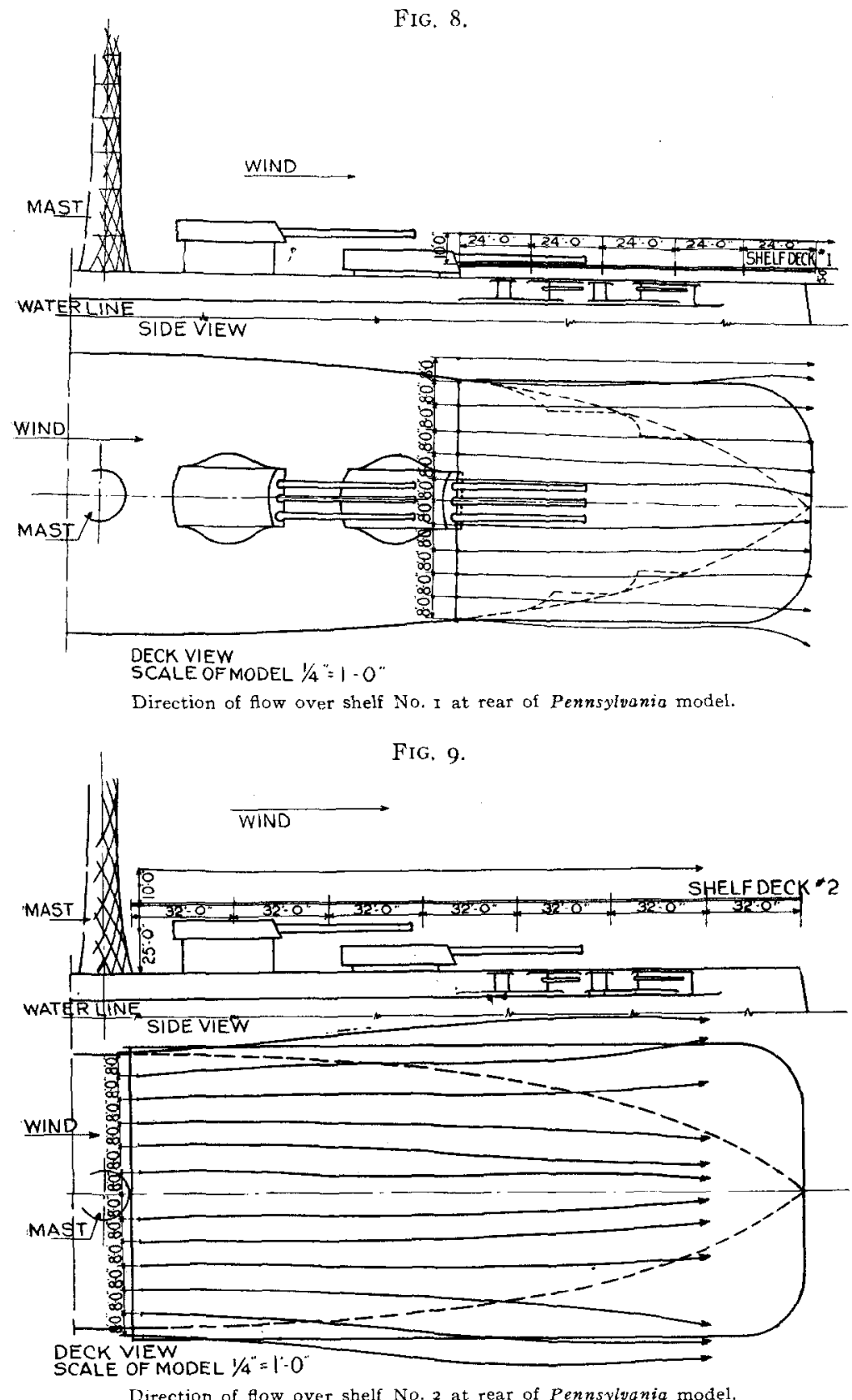

Direction of flow over shelf No. 2 at rear of Pennsyivania model. 
FIG. IO.

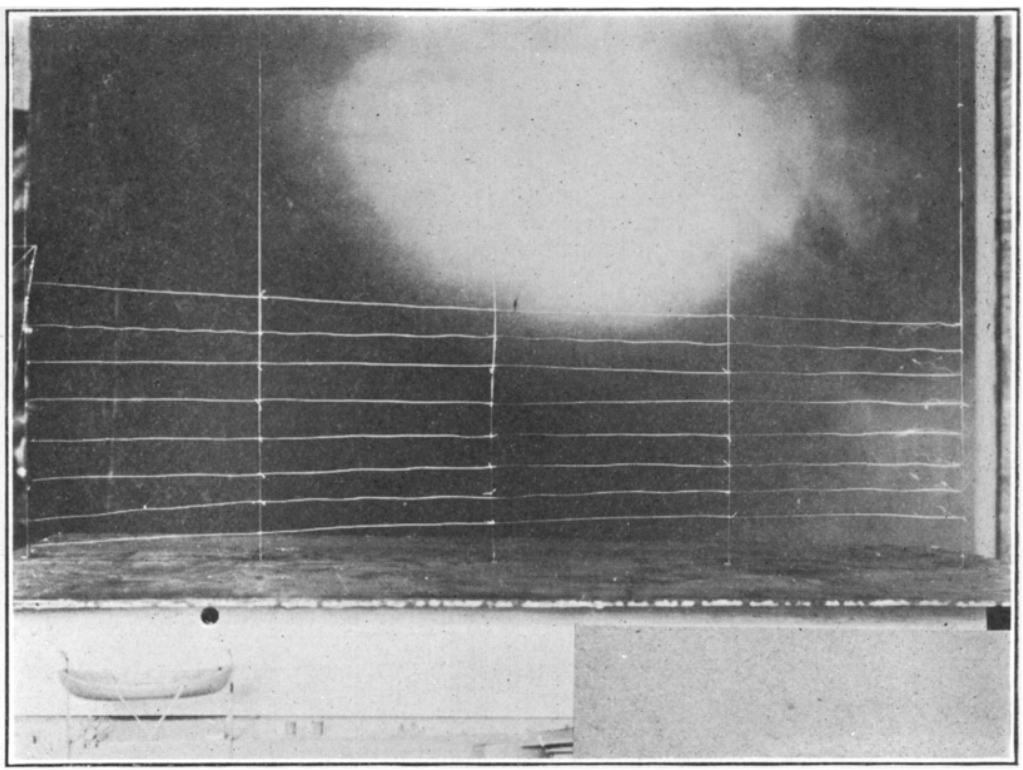

Air flow in plane of symmetry over rear shelf-deck of Pennsylvania model, lying on its side.

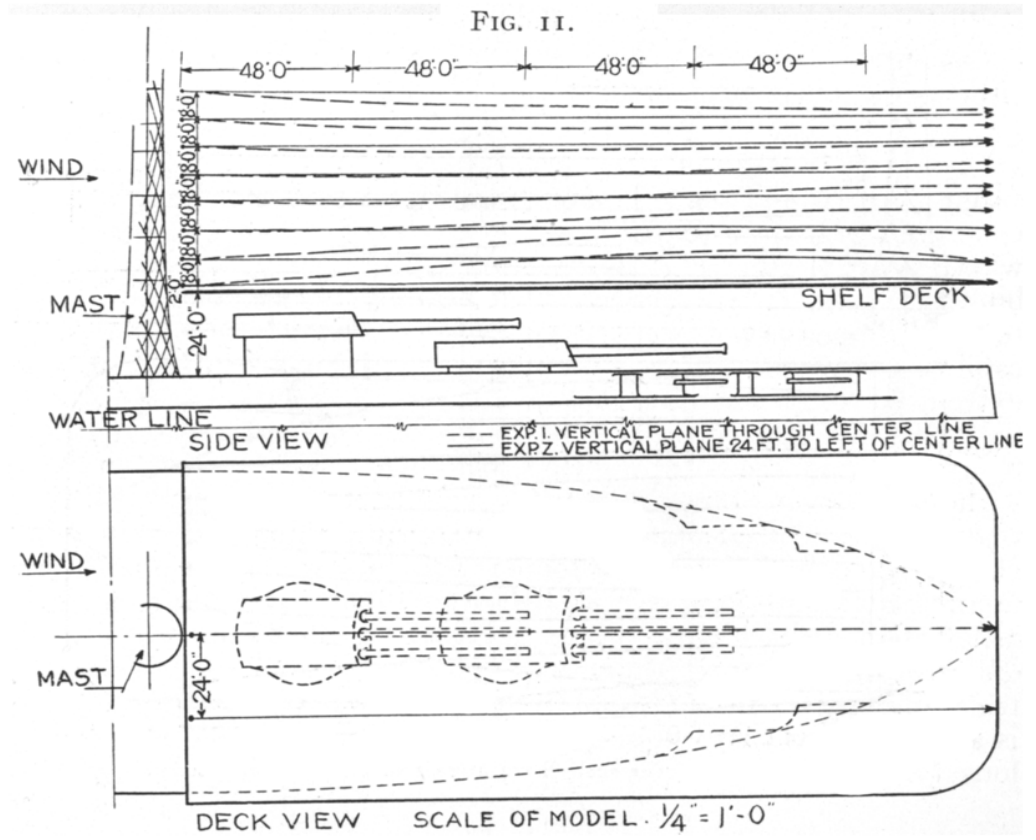

Direction of flow over shelf deck at rear of Pennsylvania model. 
character at a level i 5 feet above the main deck of the ship when furnished with a smaller shelf deck. This is probably due to irregular flow around the hull of the ship. Fig. 9 outlines the direction of flow above the larger shelf deck, in a plane 35 feet above the main deck, and indicates a slight tendency of the air stream to spill over the sides of the shelving deck. The ample beam of the vessel insures a uniform air stream broad enough to afford, with either shelf, a favorable directional flow for landing small craft upon the ship.

Further Data.-In a subsequent test, maps of the airflow with the shelf deck in position were determined at 30 miles an hour for the plane of symmetry of the vessel, and for a parallel plane half way out to the edge of the shelf on the port side. It was assumed that the flow in the corresponding plane on the starboard side would be the same. The large shelf deck described in this account was used.

Figs. Io and I s show the streamlines for these two planes. The full lines of the diagram indicate that the flow is fairly level and uniform in the planes at either side of the centre line. In the plane of symmetry the flow. indicated by the dotted lines. is considerably less uniform in speed and direction. It would appear from this that the poise of the airplane would be steadiest when flying along the centre line, and not very steady when flying to either side thereof.

Concrete-Freight Car. (Machinery, vol. xxv, No. I2, p. III4. August, 1919.) - The first plans for the manufacture of reinforced concrete freight cars dates from 1909, when a patent for such a car was granted. Recently, however, a car of the gondola type was built by a western concern and tested under service conditions. 'The tests of the car, both empty and loaded, demonstrated its practicability for rough service. In the test without a load, it withstood extremely rough handling and switching. Then the car was loaded with fifty-five tons ( Io per cent. overload) of sand and turned over to a switching crew for service handling, which it also withstood without iniury. Some advantares claimed for the concrete car are that it will not need painting, will practically eliminate maintenance charges, and will last much longer than the wooden car. As it is unaffected by its cargo, it is better adapted for hauling slag and ashes than a stecl car. Plans are said to be under way for the quantity manufacture of these cars. The first one was built with the cooperation of the United States Railroad Administration, which is an indication that extensive production may not be delayed very long. 